\title{
Mechanochemical Preparation of Cobalt Nanoparticles through a Novel Intramolecular Reaction in Cobalt(II) Complexes
}

\author{
Seyed Abolghasem Kahani and Massumeh Khedmati \\ Department of Inorganic Chemistry, Faculty of Chemistry, University of Kashan, Kashan 87317-51167, Iran \\ Correspondence should be addressed to Seyed Abolghasem Kahani; kahani@kashanu.ac.ir
}

Received 29 August 2014; Accepted 2 November 2014

Academic Editor: Nageh K. Allam

Copyright (C) 2015 S. A. Kahani and M. Khedmati. This is an open access article distributed under the Creative Commons Attribution License, which permits unrestricted use, distribution, and reproduction in any medium, provided the original work is properly cited.

\begin{abstract}
A novel solid state reaction involving a series of cobalt(II) hydrazine-azides has been used to prepare metallic cobalt nanoparticles. The reactions of $\left[\mathrm{Co}\left(\mathrm{N}_{2} \mathrm{H}_{4}\right)\left(\mathrm{N}_{3}\right)_{2}\right],\left[\mathrm{Co}\left(\mathrm{N}_{2} \mathrm{H}_{4}\right)_{2}\left(\mathrm{~N}_{3}\right)_{2}\right]$, and $\left[\mathrm{Co}\left(\mathrm{N}_{2} \mathrm{H}_{4}\right)\left(\mathrm{N}_{3}\right) \mathrm{Cl}\right] \cdot \mathrm{H}_{2} \mathrm{O}$ via $\mathrm{NaOH}, \mathrm{KOH}$ as reactants were carried out in the solid state. These complexes undergo an intramolecular two-electron oxidation-reduction reaction at room temperature, producing metallic cobalt nanoparticles (Col-Co6). The aforementioned complexes contain cobalt(II) that is an oxidizing agent and also hydrazine ligand as a reducing agent. Other products produced include sodium azide and ammonia gas. The cobalt metal nanoparticles were characterized using X-ray powder diffraction (XRD), scanning electron microscopy (SEM), and vibrating sample magnetometer (VSM). The synthesized cobalt nanoparticles have similar morphologies; however, their particle size distributions are different.
\end{abstract}

\section{Introduction}

Among the ferromagnetic elements, Co nanoparticles have a wide range of applications in catalysis, optoelectronics, magnetic recording media, and rechargeable batteries [13]. Many interesting properties were observed when magnetic metal particles were being prepared in nanoscale. For example, as particle size decreases, the surface-to-volume ratio increases, and properties which depend on this ratio change. Thus, nanoparticles show many unusual chemical and physical properties compared to bulk particles [4]. In an elaboration of this kind of approach, various methods have been developed for the synthesis of metal nanoparticles including vapor, liquid, and solid state processing routes $[5,6]$. In the literature, the top-down and the bottomup approaches are used to synthesize nanoparticles [7]. The mechanochemical synthesis is an interdisciplinary new approach between the top-down and bottom-up approaches [8]. The idea of performing reactions directly between solids, excluding the dissolving stage, is attractive to chemists because reactions in aqueous solution undergo side reactions [9]. Mechanochemistry refers to reactions that are induced by mechanical processes, milling, or grinding. The synthesis of nanocrystalline materials by mechanical milling, mechanical alloying, and mechanochemical processing has been studied [10]. On the other hand, the study of coordination mechanochemical redox reactions is still in its infancy [11,12]. The chemistry of coordination compounds is a wide area of inorganic chemistry and an enormous number of reactions are known to occur in these compounds [13]. The numerous types of reactions including ligand exchange reactions, isomerization reactions, redox reactions, and reactions of coordinated ligands have been reported in the solid state [14]. The electronic interactions between metal and ligands play a prominent role in the intramolecular reactions [15]. Consequently, intramolecular electron transfer involving metal and ligands takes place between coupled redox centers. In many cases, ligand to metal charge transfer excitation is associated with the reduction of the metal and oxidation of the ligand but in some cases the ligand serves as the source of the reducing agent [16]. Hydrazine is such a compound, and the preparation of many complexes is based on it [17]. The extensive coordination chemistry of hydrazine is evidence for this type of reaction [18]. Transition metal complexes have several unique features in reactions. The most important one is the pattern of electron transfer [19]. So far, there 
are no reports in the field of mechanochemical reduction of cobalt(II) complexes to metallic cobalt nanoparticles in any literature. In undertaking this project, $\left[\mathrm{Co}\left(\mathrm{N}_{2} \mathrm{H}_{4}\right)\left(\mathrm{N}_{3}\right)_{2}\right]$, $\left[\mathrm{Co}\left(\mathrm{N}_{2} \mathrm{H}_{4}\right)_{2}\left(\mathrm{~N}_{3}\right)_{2}\right]$, and $\left[\mathrm{Co}\left(\mathrm{N}_{2} \mathrm{H}_{4}\right)\left(\mathrm{N}_{3}\right) \mathrm{Cl}\right] \cdot \mathrm{H}_{2} \mathrm{O}$ complexes are used for the preparation of cobalt nanoparticles in the solid state. Results show that an electron is transferred from ligand to metal, and an intramolecular oxidation reduction reaction has occurred. A new preparation method of nickel nanoparticles in the solid state at room temperature has been reported [20]. Here this new method is extended to cobalt(II) complexes. These researches join the topics of the intramolecular reaction, metals, mechanochemistry, nanoscience, and coordination chemistry. Using coordination compounds as reactants in the preparation of metallic nanoparticles creates a new area of research in coordination chemistry.

\section{Experimental}

2.1. Starting Materials. All chemical reagents used in this experiment were pure grade and used without further purification. Cobalt sulfate heptahydrate, cobalt chloride hexahydrate, sodium azide, hydrazine monohydrate solution, sodium hydroxide, and potassium hydroxide were purchased from Merck. The water used throughout this work was doubly distilled water.

2.2. Synthesis of $\left[\mathrm{Co}\left(\mathrm{N}_{2} \mathrm{H}_{4}\right)\left(\mathrm{N}_{3}\right)_{2}\right]$ Complex. Using hydrazine $\left(\mathrm{N}_{2} \mathrm{H}_{4}\right)$ as a cobridge with azide, a honeycomb layered cobalt(II) coordination polymer $\left[\mathrm{Co}\left(\mathrm{N}_{2} \mathrm{H}_{4}\right)\left(\mathrm{N}_{3}\right)_{2}\right]$ is obtained as follows.

An aqueous solution $(10 \mathrm{~mL})$ of hydrazine sulfate $(0.13 \mathrm{~g}$, $1.0 \mathrm{mmol})$ and $\mathrm{CoSO}_{4} \cdot 7 \mathrm{H}_{2} \mathrm{O}(0.28 \mathrm{~g}, 1.0 \mathrm{mmol})$ was heated at $93^{\circ} \mathrm{C}$ for $10 \mathrm{~min}$ and then quickly mixed with a hot aqueous solution $(15 \mathrm{~mL})$ of excessive $\mathrm{NaN}_{3}(1.3 \mathrm{~g}, 20 \mathrm{mmol})$. The mixed purple solution was kept at $93^{\circ} \mathrm{C}$ for $10 \mathrm{~min}$ without disturbance. After slow cooling down to room temperature at $5^{\circ} \mathrm{C} / \mathrm{h}$, dark-red column crystals were obtained. The crystals were filtered and washed with distilled water and ethanol, respectively, and then dried in vacuo [21].

2.3. Synthesis of $\left[\mathrm{Co}\left(\mathrm{N}_{2} \mathrm{H}_{4}\right)_{2}\left(\mathrm{~N}_{3}\right)_{2}\right]$ Complex. $\operatorname{Co}\left(\mathrm{N}_{3}\right)_{2}$ in solution was obtained by reacting the cobalt(II) chloride with sodium azide solution 1:2. Cobalt(II) azide molar ratios $\mathrm{CoCl}_{2} \cdot 6 \mathrm{H}_{2} \mathrm{O}(4.80 \mathrm{~g}, 20 \mathrm{mmol})$ reacted with $\mathrm{NaN}_{3}$ $(2.60 \mathrm{~g}, 40 \mathrm{mmol})$ in $50 \mathrm{~mL}$ water. Stoichiometry amounts of hydrazine hydrate $(2.40 \mathrm{~g}, 40 \mathrm{mmol})$ were added to the $\mathrm{Co}\left(\mathrm{N}_{3}\right)_{2}$ solution. The solutions were continuously stirred in an ice bath for $0.5 \mathrm{~h}$. The solid complex, thus obtained, was filtered and washed with dilute ethanol and dried over anhydrous calcium chloride [22].

2.4. Synthesis of $\left[\mathrm{Co}\left(\mathrm{N}_{2} \mathrm{H}_{4}\right)\left(\mathrm{N}_{3}\right) \mathrm{Cl}\right] \cdot \mathrm{H}_{2} \mathrm{O}$ Complex. $\mathrm{Co}\left(\mathrm{N}_{3}\right) \mathrm{Cl}$ in solution was obtained by reacting the cobalt(II) chloride with sodium azide solution 1:1 molar ratios in $50 \mathrm{~mL}$ water. Stoichiometry amounts of hydrazine hydrate $(1.20 \mathrm{~g}$, $20 \mathrm{mmol}$ ) were added to the $\mathrm{Co}\left(\mathrm{N}_{3}\right) \mathrm{Cl}$ solution. The solutions were continuously stirred in an ice bath for $0.5 \mathrm{~h}$. The solid complex, thus obtained, was filtered and washed with dilute ethanol and dried over anhydrous calcium chloride [22].
2.5. The Mechanochemical Synthesis of Cobalt Nanoparticles. A mixture $0.175 \mathrm{~g}(0.1 \mathrm{mmole})$ of $\left[\mathrm{Co}\left(\mathrm{N}_{2} \mathrm{H}_{4}\right)\left(\mathrm{N}_{3}\right)_{2}\right]$ complex and $0.5 \mathrm{~g}$ (12.5 mmole) sodium hydroxide in excess was loaded into a mortar pestle of $50 \mathrm{~mL}$ capacity. The stoichiometry of reactions between cobalt(II) hydrazine complex and alkali bases $(\mathrm{NaOH}, \mathrm{KOH})$ was $1: 2.5$, and grinding was carried out for $1 \mathrm{~h}$. For the purification process, the product was transferred to a beaker and washed. The product (Col) was washed with methanol, filtered, and dried in a vacuum oven at room temperature for a period of at least $24 \mathrm{~h}$. A similar procedure for the preparation of $\mathrm{Co} 2$ from $\left[\mathrm{Co}\left(\mathrm{N}_{2} \mathrm{H}_{4}\right)_{2}\left(\mathrm{~N}_{3}\right)_{2}\right]$ $(0.207 \mathrm{~g}, 0.1 \mathrm{mmole})$ and $\mathrm{NaOH}(0.5 \mathrm{~g}, 12.5 \mathrm{mmole})$ is carried out. In the reaction between $\left[\mathrm{Co}\left(\mathrm{N}_{2} \mathrm{H}_{4}\right)\left(\mathrm{N}_{3}\right) \mathrm{Cl}\right] \cdot \mathrm{H}_{2} \mathrm{O}$ complex (0.203 g, 0.1 mmole) and $\mathrm{NaOH}(0.5 \mathrm{~g}, 12.5 \mathrm{mmole})$, $\mathrm{Co} 3$ nanoparticles were produced. In the preparation of Co4, Co5, and Co6 the mole ratio is similar to Co1, Co2, and Co3, respectively. However, in the preparation of Co4, Co5, and $\mathrm{Co6}$, the alkaline reactant is $\mathrm{KOH}$. In the solid phase, an intramolecular redox chemical reaction between ligand and central atom occurred, and cobalt metal generated ((1), (2), and (3)). The following reactions take place at room temperature in the solid phase:

$$
\begin{aligned}
& {\left[\mathrm{Co}\left(\mathrm{N}_{2} \mathrm{H}_{4}\right)\left(\mathrm{N}_{3}\right)_{2}\right]+\frac{5}{2} \mathrm{NaOH}} \\
& \longrightarrow \frac{1}{2} \mathrm{NH}_{3}+\frac{5}{2} \mathrm{NaN}_{3}+\mathrm{Co}+\frac{5}{2} \mathrm{H}_{2} \mathrm{O} \\
& {\left[\mathrm{Co}\left(\mathrm{N}_{2} \mathrm{H}_{4}\right)_{2}\left(\mathrm{~N}_{3}\right)_{2}\right]+\frac{5}{2} \mathrm{NaOH}} \\
& \longrightarrow \frac{1}{2} \mathrm{NH}_{3}+\frac{5}{2} \mathrm{NaN}_{3}+\mathrm{Co}+\frac{5}{2} \mathrm{H}_{2} \mathrm{O}+\mathrm{N}_{2} \mathrm{H}_{4} \\
& {\left[\mathrm{Co}\left(\mathrm{N}_{2} \mathrm{H}_{4}\right)\left(\mathrm{N}_{3}\right) \mathrm{Cl}\right] \cdot \mathrm{H}_{2} \mathrm{O}+\frac{5}{2} \mathrm{NaOH}^{\longrightarrow} \frac{1}{2} \mathrm{NH}_{3}+\frac{3}{2} \mathrm{NaN}_{3}+\mathrm{Co}+\frac{7}{2} \mathrm{H}_{2} \mathrm{O}+\mathrm{NaCl}}
\end{aligned}
$$

Similar reactions occurred in the presence of $\mathrm{KOH}$ as alkaline in solid state reaction. During the milling of reactants in the redox reactions ammonia gas is released, and $\mathrm{NaN}_{3}$ was produced. Ammonia combines with hydrochloric acid and forms ammonium chloride. Colorimetric testing can be used to detect $\mathrm{NaN}_{3}$ [23]. A drop of the filtered solution is placed in the depression of a spot plate and treated with 1 or 2 drops of dilute hydrochloric acid. A drop of ferric chloride solution is added and the spot plate gently heated. A red color indicates hydrazoic acid and thus the presence of sodium azide in the solution.

2.6. Characterization of Materials. The cobalt complex and cobalt powders were characterized by X-ray powder diffraction (XRD). XRD measurements were performed using a Philips X'pert pro MPD diffractometer with $\mathrm{Cu} \mathrm{K} \alpha$ radiation in the range $2 \theta$ from 10 to 80 at room temperature. IR spectra were obtained as $\mathrm{KBr}$ pellets in the range 4000 to $400 \mathrm{~cm}^{-1}$ using a Shimadzu FTIR spectrometer. Scanning electron microscopy (Philips XL30ESEM) was used to characterize cobalt nanoparticles. A vibrating sample magnetometer 
(VSM, Meghnatis Daghigh Kavir Co.) was used to evaluate the magnetic parameters of cobalt nanoparticles.

\section{Results and Discussion}

In the solid state $\left[\mathrm{Co}\left(\mathrm{N}_{2} \mathrm{H}_{4}\right)\left(\mathrm{N}_{3}\right)_{2}\right],\left[\mathrm{Co}\left(\mathrm{N}_{2} \mathrm{H}_{4}\right)_{2}\left(\mathrm{~N}_{3}\right)_{2}\right]$, and $\left[\mathrm{Co}\left(\mathrm{N}_{2} \mathrm{H}_{4}\right)\left(\mathrm{N}_{3}\right) \mathrm{Cl}\right] \cdot \mathrm{H}_{2} \mathrm{O}$ undergo an intramolecular twoelectron oxidation reduction reaction. These reactions under alkaline condition $(\mathrm{NaOH}, \mathrm{KOH})$ lead to formation of cobalt metal, azide, and ammonia. Depending on the oxidizing agent, $\mathrm{pH}$, and temperature, hydrazine reacts in different pathways. In aqueous solution, hydrazine reacts as one, two, or four electron oxidation paths and is converted to a mixture of dinitrogen and ammonia, azide, and ammonia and/or only dinitrogen, respectively. The redox reactions of hydrazine cobalt(II) complexes have several unique features, the most important of them being the patterns of electron transfer from ligand to metal. On the other hand, these mechanochemical reactions occurred at room temperature, and the final main product is metallic cobalt nanoparticles. In this work, the cobalt nanoparticles are prepared with different shapes by using a mechanochemical route. However, when the cobalt complex as a reactant was used in aqueous solution, cobalt nanoparticles with different morphologies were formed [24]. The metallic cobalt nanoparticles were characterized using XRD, IR, VSM, and SEM analysis.

3.1. Analysis of Metallic Cobalt Nanoparticles Crystalline Phase. According to the XRD pattern in the literature, $\left[\mathrm{Co}\left(\mathrm{N}_{2} \mathrm{H}_{4}\right)\left(\mathrm{N}_{3}\right)_{2}\right]$ crystallizes in the orthorhombic system and space group C2221. This complex is showed as a cobridge with azide and hydrazine and honeycomb layered cobalt(II) coordination polymer [21]. However, XRD patterns and crystal structure of $\left[\mathrm{Co}\left(\mathrm{N}_{2} \mathrm{H}_{4}\right)_{2}\left(\mathrm{~N}_{3}\right)_{2}\right]$ and $\left[\mathrm{Co}\left(\mathrm{N}_{2} \mathrm{H}_{4}\right)\left(\mathrm{N}_{3}\right) \mathrm{Cl}\right] \cdot \mathrm{H}_{2} \mathrm{O}$ have not been reported. During solid state reactions, all complexes are converted to metallic cobalt; thus, all diffraction peaks related to complex patterns disappeared. In accordance with the diffraction pattern analyses, it could be concluded that the nanoparticles prepared in this work were pure hcp cobalt. The cobalt nanoparticles have JCPDS card no. 05-0727 and P63/mmc space group. The mechanochemical reaction of cobalt(II) complex to metallic cobalt is accompanied by a change in the crystal structure. All the diffraction peaks can be well indexed to hcp phase cobalt, with lattice constants of $a_{0}=2.5031 \AA c_{0}=4.0605 \AA$. The fundamental difference between crystalline and amorphous solids is due to their X-ray diffraction patterns. However, poor crystallinity of the powder results in broad peaks in the $\mathrm{X}$-ray pattern. There are different lines broadening sources, such as crystallite size, lattice strain, anisotropic sample broadening, and faulting, tending to produce different effects on the line profiles. Here in the metallic cobalt pattern the background noise from fluoresced X-rays is increased, which is most problematic in powder diffraction (Figure 1). The choice of X-ray source in X-ray powder diffraction is dependent on the material that must be analyzed. Some atoms absorb incident $\mathrm{X}$-rays and fluoresce by the absorption of X-rays, which decreases the diffracted signal, and also the fluoresced X-rays increase the background noise. When

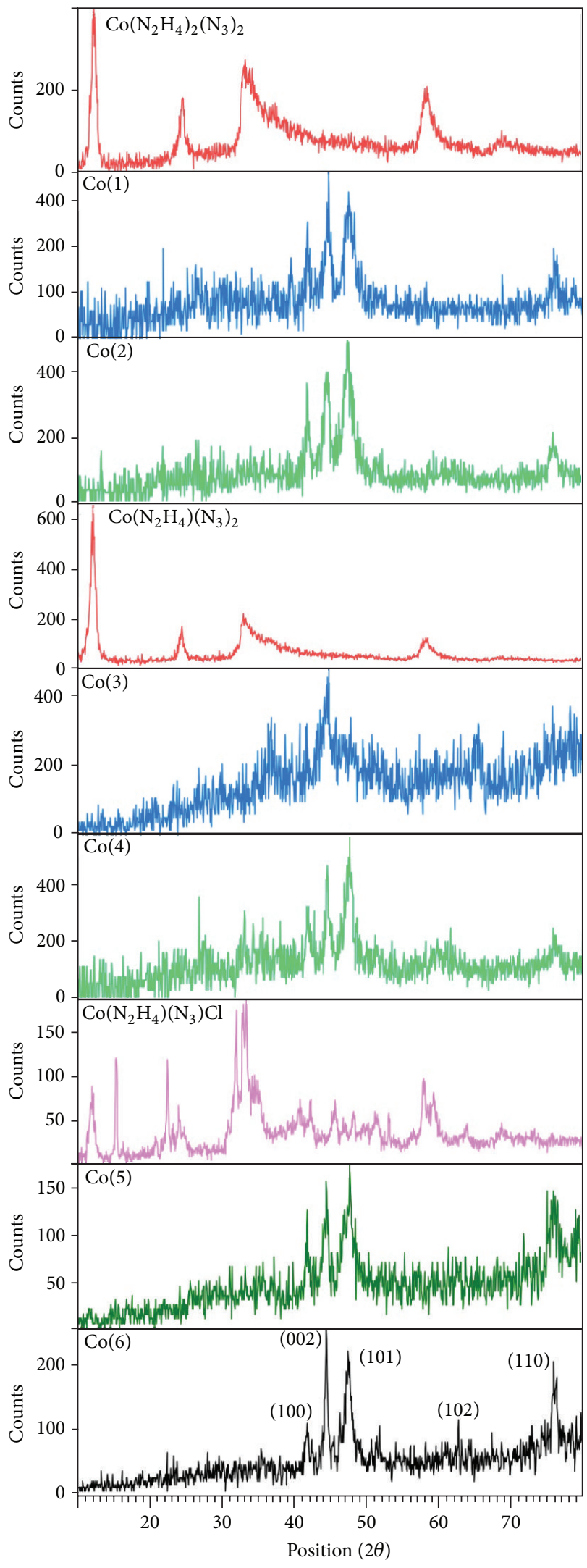

Figure 1: X-ray diffraction patterns of the $\operatorname{Co}\left(\mathrm{N}_{2} \mathrm{H}_{4}\right)\left(\mathrm{N}_{3}\right)_{2}$, $\mathrm{Co}\left(\mathrm{N}_{2} \mathrm{H}_{4}\right)_{2}\left(\mathrm{~N}_{3}\right)_{2}$, and $\mathrm{Co}\left(\mathrm{N}_{2} \mathrm{H}_{4}\right)\left(\mathrm{N}_{3}\right) \mathrm{Cl}$ and their products, cobalt metal nanoparticles (Co1-Co6), in hcp lattice. 


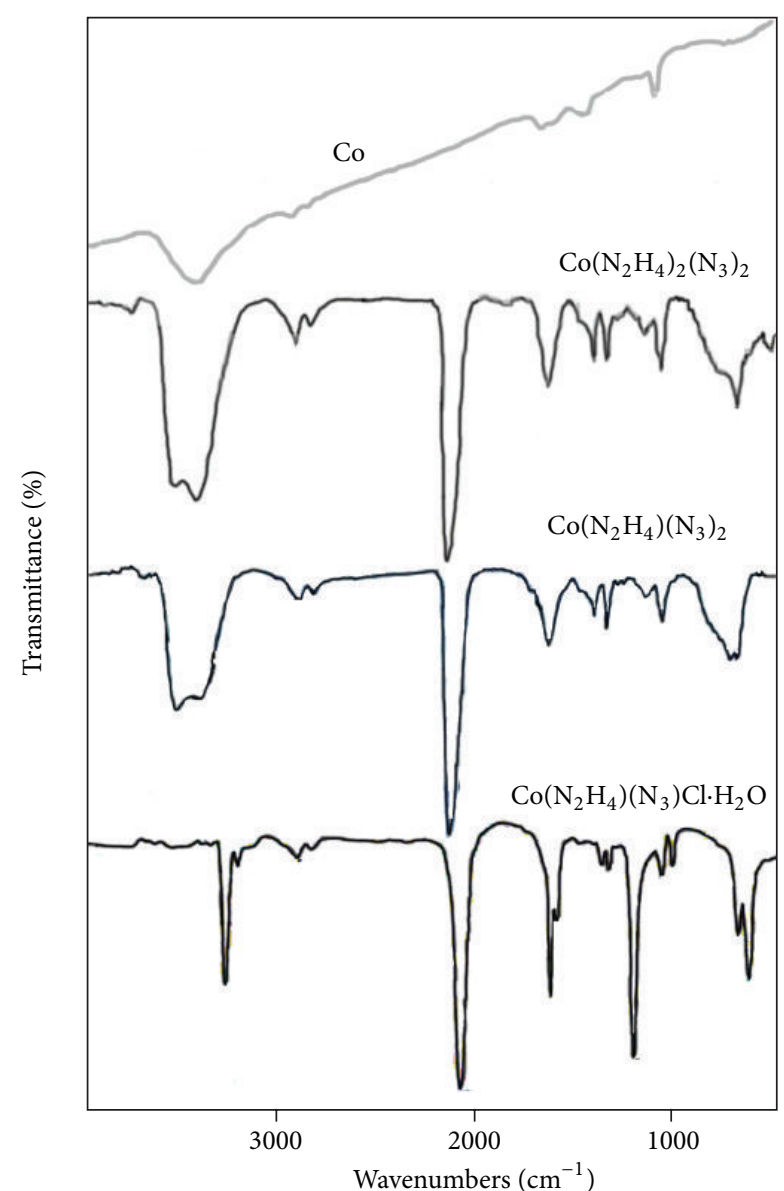

FIgURE 2: IR spectra of $\mathrm{Co}\left(\mathrm{N}_{2} \mathrm{H}_{4}\right)\left(\mathrm{N}_{3}\right)_{2}, \mathrm{Co}\left(\mathrm{N}_{2} \mathrm{H}_{4}\right)_{2}\left(\mathrm{~N}_{3}\right)_{2}$, and $\mathrm{Co}\left(\mathrm{N}_{2} \mathrm{H}_{4}\right)\left(\mathrm{N}_{3}\right) \mathrm{Cl}$ in the region $400-4000 \mathrm{~cm}^{-1}$, and cobalt nanoparticles (Co1-Co6) are produced, and all the absorption bands disappear.

copper radiation is employed, the X-ray powder pattern of cobalt nanoparticles demonstrates the effect of fluorescence on the diffraction pattern [25]. Therefore there is an uncertainty in the estimation of crystallite size from the full width at half maximum (FWHM) of the diffraction peaks by the Scherrer formula. The pattern of X-ray diffraction shows the crystalline structure of final products. All the diffraction peaks can be well indexed to the hexagonal phase of cobalt.

\subsection{Infrared Spectra of Complexes and Cobalt Nanoparticles.} Vibration spectra of $\left[\mathrm{Co}\left(\mathrm{N}_{2} \mathrm{H}_{4}\right)\left(\mathrm{N}_{3}\right)_{2}\right],\left[\mathrm{Co}\left(\mathrm{N}_{2} \mathrm{H}_{4}\right)_{2}\left(\mathrm{~N}_{3}\right)_{2}\right]$, and $\left[\mathrm{Co}\left(\mathrm{N}_{2} \mathrm{H}_{4}\right)\left(\mathrm{N}_{3}\right) \mathrm{Cl}\right] \cdot \mathrm{H}_{2} \mathrm{O}$ show $\mathrm{N}_{2} \mathrm{H}_{4}$ and azido vibrations frequencies (Figure 2). Hydrazine coordinates to a $\mathrm{Co}(\mathrm{II})$ as a bridging bidentate ligand showing bands (NN) near $970 \mathrm{~cm}^{-1}$ [26]. Here the azido vibrations appear at 2010-2050, 1260-1350, and 610-670 $\mathrm{cm}^{-1}$. The antisymmetric and symmetric $\mathrm{N}_{3}{ }^{-}$stretching absorption bands occur at 2010-2050 $\mathrm{cm}^{-1}$ and $1260-1350$, respectively; the deformation stretching also was observed at $610-670 \mathrm{~cm}^{-1}$ [27]. In the chemical reaction, the cobalt complexes are converted to cobalt metal nanoparticles (Co1-Co6); thus, the absorption bands due to ligands group in complexes disappeared and
TABLE 1: Magnetic parameters in cobalt metal nanoparticles that have been measured at $298 \mathrm{~K}$.

\begin{tabular}{lccc}
\hline Sample & $H_{c}(\mathrm{Oe})$ & $M_{r}(\mathrm{emu} / \mathrm{g})$ & $M_{S}(\mathrm{emu} / \mathrm{g})$ \\
\hline Co1 & 398.05 & 20.19 & 135.45 \\
Co2 & 341.18 & 15.49 & 99.62 \\
Co3 & 389.92 & 15.33 & 88.33 \\
Co4 & 471.16 & 11.72 & 68.68 \\
Co5 & 398.05 & 19.48 & 113.92 \\
Co6 & 235.58 & 15.48 & 119.18 \\
\hline
\end{tabular}

the metallic cobalt nanoparticles have no absorption bands in medium IR.

3.3. Magnetic Properties of Metallic Cobalt Nanoparticles. Cobalt nanoparticles were prepared from $\left[\mathrm{Co}\left(\mathrm{N}_{2} \mathrm{H}_{4}\right)\left(\mathrm{N}_{3}\right)_{2}\right]$, $\left[\mathrm{Co}\left(\mathrm{N}_{2} \mathrm{H}_{4}\right)_{2}\left(\mathrm{~N}_{3}\right)_{2}\right]$, and $\left[\mathrm{Co}\left(\mathrm{N}_{2} \mathrm{H}_{4}\right)\left(\mathrm{N}_{3}\right) \mathrm{Cl}\right] \cdot \mathrm{H}_{2} \mathrm{O}$ by chemical redox reaction in solid state. The magnetic susceptibility reveals paramagnetic and a week interaction between cobalt(II) ions in the polynuclear complex [21]. The conversion of cobalt(II) complexes to metallic cobalt can be accompanied by a change in magnetization. These molecular paramagnetic complexes are changed into ferromagnetic cobalt metal nanoparticles (Figure 3). The saturation magnetization $\left(M_{S}\right)$ values of Co1, Co2, Co3, Co4, Co5, and Co6 at $298 \mathrm{~K}$ were 135.45, 99.62, 88.33, 68.68, 113.92, and $119.18 \mathrm{emu} / \mathrm{g}$, respectively (Table 1). Here the cobalt nanoparticles have a saturation magnetization less than that of the bulk cobalt. The $M_{S}$ value of the bulk cobalt was about $162.5 \mathrm{emu} / \mathrm{g}$ at $300 \mathrm{~K}$. It is known that the magnetization behavior of a magnetic material is highly size dependent. Despite the endless number of reports on magnetic studies of magnetic nanoparticles the influence of particle size on the magnetic properties has not been systematically studied [28]. The metallic cobalt nanoparticles show magnetic parameters such as saturation magnetization and coercivity that vary with particle size, usually in a nonlinear fashion $[29,30]$. It is envisaged that the application of Co nanoparticles can be expanded once the intrigue relationship between magnetic properties and particle size of Co can be delineated. The large magnetic particle contains mobile walls when the size of the particle decreases below a critical size, the domain walls disappear, and the particles become single domain. Magnetic particles in the nanometer-size range are necessarily single-magneticdomain structures. The critical size depends on the saturated magnetization, anisotropy energy, and exchange interaction between individual spins [31].

3.4. Analysis of Cobalt Particles Morphologies. Figure 4 shows an SEM image of a typical cobalt particle prepared via intramolecular chemical reduction. Morphology of the cobalt nanoparticles was dependent on the complex structure as reactant. The SEM of $\mathrm{Co} 1$ and $\mathrm{Co} 2$ show aggregated pore structure containing the nanosheets and nanosheet thickness ranging from $35 \mathrm{~nm}$ to $60 \mathrm{~nm}$. An aggregated spherical particle without pore is observed in $\mathrm{Co} 3$ and $\mathrm{Co} 4$, and their particle sizes are ranging from $50 \mathrm{~nm}$ to $80 \mathrm{~nm}$. The Co5 and Co6 nanoparticles have pore structure containing the nanosheets 

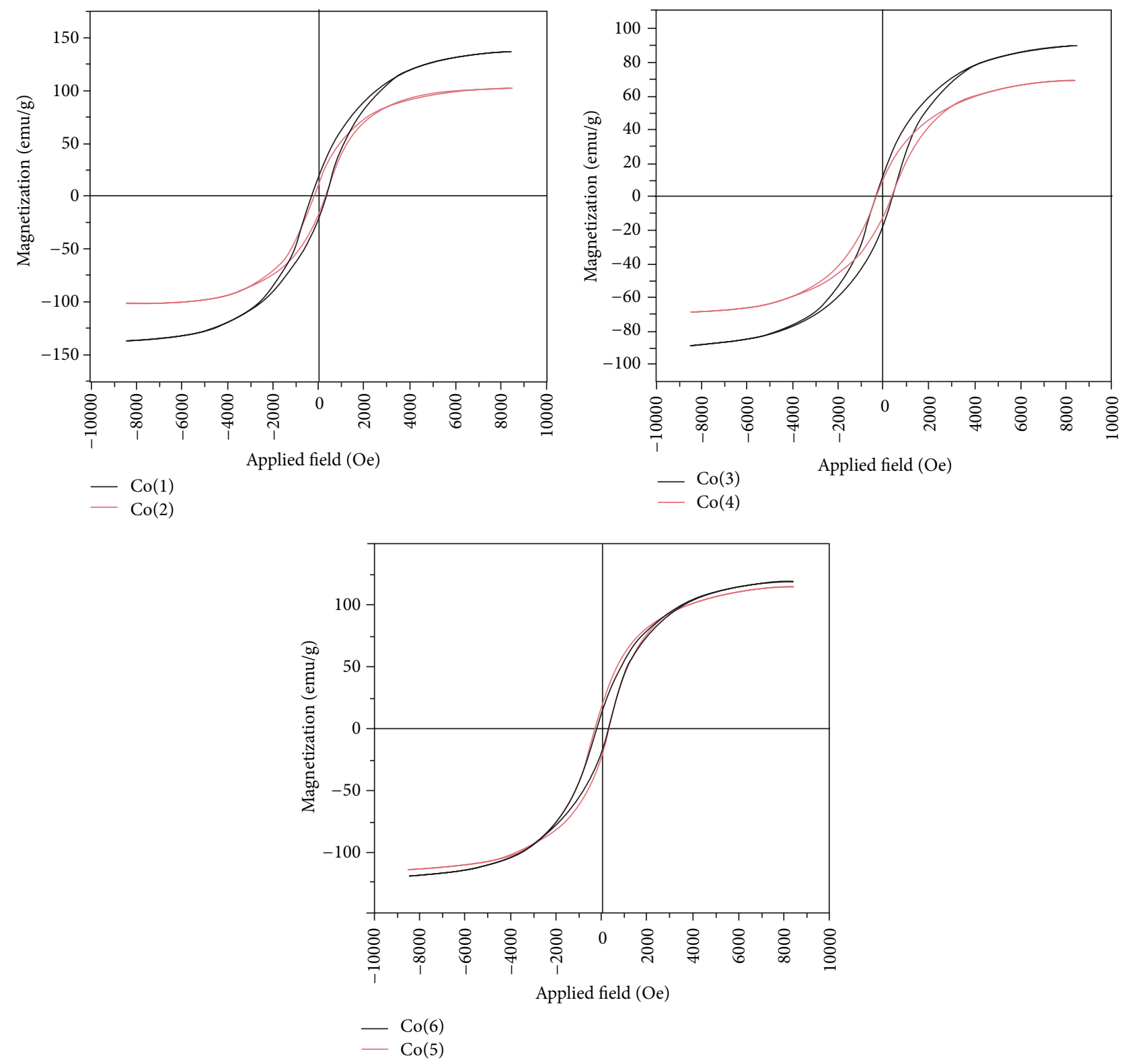

FIGURE 3: Hysteresis loop and the saturation magnetizations of cobalt nanoparticles have been measured at $298 \mathrm{~K}(\mathrm{Co1}=135.45$, Co2 $=99.62$, $\mathrm{Co} 3=88.33, \mathrm{Co} 4=68.68, \operatorname{Co} 5=113.92$, and Co6 $=119.18 \mathrm{emu} / \mathrm{g}$ ), respectively.

and nanosheet thickness ranging from $25 \mathrm{~nm}$ to $35 \mathrm{~nm}$. The statistical analysis shows that Col, Co2, Co5, and Co6 nanoparticles have similar morphology, whereas $\mathrm{Co} 3$ and Co4 nanoparticles have a different morphology. The results show that when polynuclear complex $\left[\mathrm{Co}\left(\mathrm{N}_{2} \mathrm{H}_{4}\right)\left(\mathrm{N}_{3}\right)_{2}\right]$ is used in the reaction, the product changes to aggregated without pore and nanosheet cobalt nanoparticles. However when mononuclear complexes $\left[\mathrm{Co}\left(\mathrm{N}_{2} \mathrm{H}_{4}\right)_{2}\left(\mathrm{~N}_{3}\right)_{2}\right]$ and $\left[\mathrm{Co}\left(\mathrm{N}_{2} \mathrm{H}_{4}\right)\left(\mathrm{N}_{3}\right) \mathrm{Cl}\right] \cdot \mathrm{H}_{2} \mathrm{O}$ are used, the complex is converted to an aggregated powder of $\mathrm{Co} 1, \mathrm{Co} 2, \mathrm{Co} 5$, and $\mathrm{Co} 6$, respectively. On the other hand the results show that when alkaline media are changed from $\mathrm{NaOH}$ to $\mathrm{KOH}$, respectively, the morphology of metallic cobalt nanoparticles has significantly changed. In the new solid state method an intramolecular chemical reduction of the cobalt complex causes the formation of particles in the nanoscale range. Besides XRD patterns and SEM micrographs of metallic cobalt phase formation are confirmed by using the energy-dispersive X-ray (EDX) data. The EDX spectra acquired at low magnification of the powders are shown in Figure 5. Energy-dispersive X-ray analysis of these prepared cobalt nanoparticles, show that they are all pure.

\section{Conclusions}

The common method is used in the preparation of metallic cobalt nanoparticles which is the chemical reduction of cobalt(II) salts by hydrazine in alcoholic solution at $60-70^{\circ} \mathrm{C}$. 

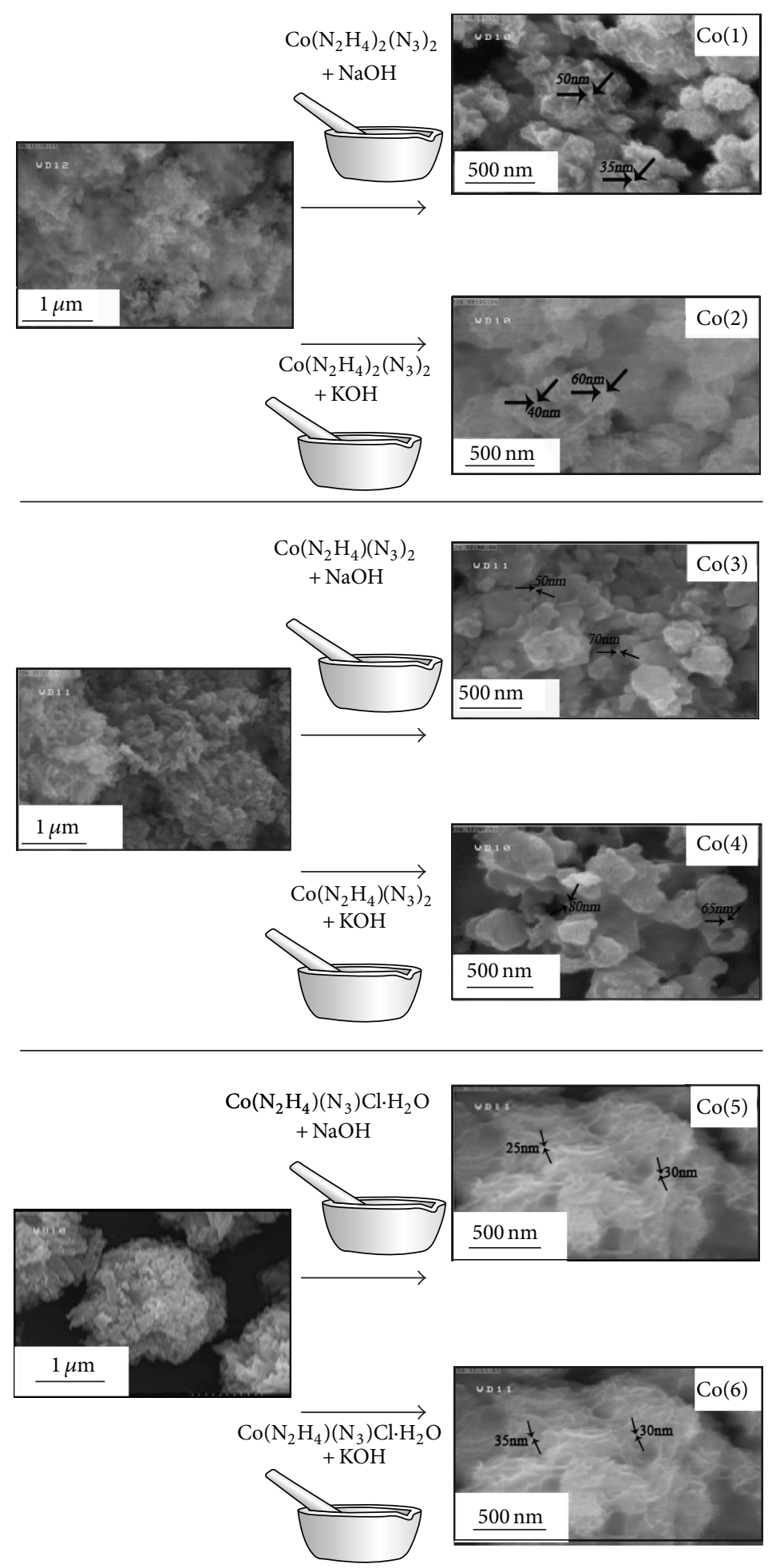

FIGURE 4: SEM show morphologies and particle size distributions in metallic cobalt nanoparticles (Co1 and Co2) aggregated nanosheet with thickness 35-60 nm; (Co3 and Co4) aggregated spherical particles with size 50-80 nm; (Co5 and Co6) aggregated nanosheet with thickness 25-35 nm. 


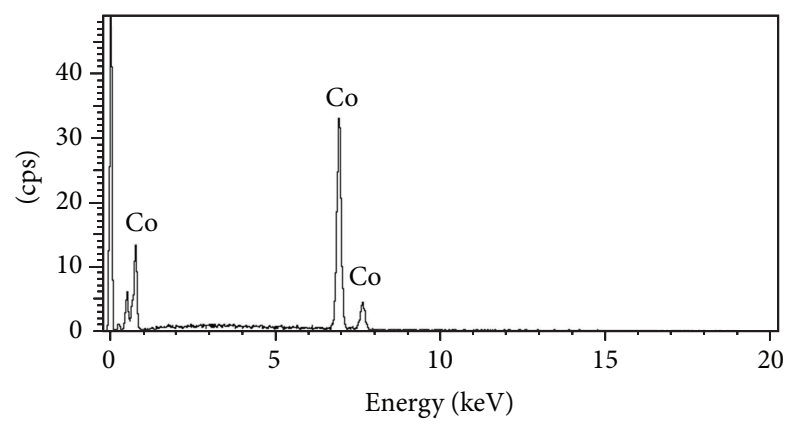

FIgURE 5: Energy-dispersive X-ray spectrum of metallic cobalt nanoparticle that is prepared from $\mathrm{Co}\left(\mathrm{N}_{2} \mathrm{H}_{4}\right)\left(\mathrm{N}_{3}\right)_{2}$ complex.

There are many substances that contributed in the reactions and the high temperature causes many side reactions on metallic nanoparticle. Here we proposed a new method for the preparation of cobalt nanoparticles in the solid state at room temperature. Besides being able to react at room temperature conditions, the complex has both oxidizing and reducing properties. In all aqueous preparation of metallic cobalt by hydrazine a $4 \mathrm{e}^{-}$oxidation reduction pathway has been reported but here we observed a new $2 \mathrm{e}^{-}$oxidation reduction pathway in the solid state reaction. This is a new methodology in the intramolecular reaction at room temperature. Fine cobalt powders with a different morphology were prepared from cobalt(II) hydrazine complexes by intramolecular redox reaction in solid state. Here depending on the interaction between the metal ion and ligands a special cobalt(II) complex for intramolecular redox reaction is designed. Therefore, the coordination sphere of complex has a profound effect on the intramolecular redox reaction. The results show that when complexes and alkaline media are changed the morphology of metallic cobalt nanoparticles has significantly changed. However, the cobalt metal is produced from $\left[\mathrm{Co}\left(\mathrm{N}_{2} \mathrm{H}_{4}\right)\left(\mathrm{N}_{3}\right)_{2}\right]$ complex and has completely different morphology than ones prepared from $\left[\mathrm{Co}\left(\mathrm{N}_{2} \mathrm{H}_{4}\right)_{2}\left(\mathrm{~N}_{3}\right)_{2}\right]$ and $\left[\mathrm{Co}\left(\mathrm{N}_{2} \mathrm{H}_{4}\right)\left(\mathrm{N}_{3}\right) \mathrm{Cl}\right] \cdot \mathrm{H}_{2} \mathrm{O}$. The advantages of this work for preparing the metallic powders lie in variation on morphology, the high yield, and solid state reaction conditions. In comparison with the method of preparing cobalt powders from cobalt(II) salts in aqueous solution, the intramolecular redox reaction of cobalt(II) hydrazine complexes show a high purity of metal cobalt. Therefore, mechanochemical intramolecular redox reaction is attractive and offers a new method in preparation of metallic cobalt nanoparticle.

\section{Conflict of Interests}

The authors declare that there is no conflict of interests regarding the publication of this paper.

\section{Acknowledgment}

The authors are grateful to University of Kashan for supporting this work by Grant no. 256736/8.

\section{References}

[1] S. P. Gubin, Magnetic Nanoparticles, Wiley, 2009.

[2] S. A. Kahani and H. Molaei, "Cobalt(III) ammine complexes as precursors in the synthesis of cobalt nanoparticles," Journal of Coordination Chemistry, vol. 66, no. 24, pp. 4430-4440, 2013.

[3] J. P. Liu, E. Fullerton, O. Gutfleisch, and D. J. Sellmyer, Nanoscale Magnetic Materials and Applications, Springer, 2009.

[4] E. Roduner, Nanoscopic Materials: Size-Dependent Phenomena, The Royal Society of Chemistry, 2007.

[5] J. A. Blackman, "Metallic nanoparticles," in Handbook of Metal Physics, P. Misra, Ed., Elsevier, Amsterdam, The Netherlands, 2009.

[6] B. L. Cushing, V. L. Kolesnichenko, and C. J. O’Connor, "Recent advances in the liquid-phase syntheses of inorganic nanoparticles," Chemical Reviews, vol. 104, no. 9, pp. 3893-3946, 2004.

[7] C. Altavilla and E. Ciliberto, Inorganic Nanoparticles: Synthesis, Applications, and Perspectives, CRC Press, 2011.

[8] P. Balaz, Mechanochemistry in Nanoscience and Minerals Engineering, Springer, 2008.

[9] S. A. Kahani and M. Sabeti, "The mechanochemical oxidation of thiocyanate to polythiocyanogen ( $\mathrm{SCN})_{n}$ using peroxydisulphate," Journal of Inorganic and Organometallic Polymers and Materials, vol. 21, no. 3, pp. 458-464, 2011.

[10] M. K. Beyer and H. Clausen-Schaumann, "Mechanochemistry: the mechanical activation of covalent bonds," Chemical Reviews, vol. 105, no. 8, pp. 2921-2948, 2005.

[11] J. E. House Jr., "Mechanistic considerations for anation reactions in the solid state," Coordination Chemistry Reviews, vol. 128, no. 1-2, pp. 175-191, 1993.

[12] E. C. Constable, Metals and Ligand Reactivity, Wiley-VCH, New York, NY, USA, 1996.

[13] J. F. Fernández-Bertran, "Mechanochemistry: an overview," Pure and Applied Chemistry, vol. 71, no. 4, pp. 581-586, 1999.

[14] V. V. Boldyrev and K. Tkáčová, "Mechanochemistry of solids: past, present, and prospects," Journal of Materials Synthesis and Processing, vol. 8, no. 3-4, pp. 121-132, 2000.

[15] H. Taube, "Electron transfer between metal complexes: retrospective," Science, vol. 226, no. 4678, pp. 1028-1036, 1984.

[16] M. Anbar, "Oxidation or reduction of ligands by metal ions in unstable states of oxidation," in Mechanisms of Inorganic Reactions, vol. 49 of Advances in Chemistry, chapter 6, pp. 126152, American Chemical Society, Washington, DC, USA, 1965.

[17] J. R. Dilworth, "The coordination chemistry of substituted hydrazines," Coordination Chemistry Reviews, vol. 21, no. 1, pp. $29-62,1976$.

[18] B. T. Heaton, C. Jacob, and P. Page, “Transition metal complexes containing hydrazine and substituted hydrazines," Coordination Chemistry Reviews, vol. 154, pp. 193-229, 1996.

[19] E. Schmidt, Hydrazine and Its Derivatives, Wiley, New York, NY, USA, 1984.

[20] S. A. Kahani and M. Khedmati, "The preparation of nickel nanoparticles through a novel solid-state intramolecular reaction of polynuclear nickel(II) complex," Journal of Nanoparticle Research, vol. 16, no. 8, pp. 2544-2546, 2014.

[21] X.-T. Wang, Z.-M. Wang, and S. Gao, "Honeycomb layer of cobalt(II) azide hydrazine showing weak ferromagnetism," Inorganic Chemistry, vol. 46, no. 25, pp. 10452-10454, 2007. 
[22] K. C. Pati, C. Nesamani, and V. R. P. Verneker, "Synthesis and characterisation of metal hydrazine nitrate, azide and perchlorate complexes," Synthesis and Reactivity in Inorganic and MetalOrganic Chemistry, vol. 12, pp. 10452-10454, 1982.

[23] J. Kurzawa, K. Janowicz, and A. Suszka, "Stopped-flow kinetic determination of thiocyanates and thiosulphates with the application of iodine-azide reaction," Analytica Chimica Acta, vol. 431, no. 1, pp. 149-155, 2001.

[24] W. Gong, H. Li, Z. Zhao, and J. Chen, "Ultrafine particles of Fe, Co, and Ni ferromagnetic metals," Journal of Applied Physics, vol. 69, pp. 5119-5121, 1991.

[25] B. D. Cullity and S. R. Stock, Elements of X-Ray Diffraction, Prentice Hall, 3rd edition, 2001.

[26] D. Nicholls and R. Swindells, "Hydrazine complexes of nickel(II) chloride," Journal of Inorganic and Nuclear Chemistry, vol. 30, no. 8, pp. 2211-2217, 1968.

[27] K. Nakamoto, Infrared and Raman Spectra of Inorganic and Coordination Compounds Part B, John Wiley \& Sons, New York, NY, USA, 5th edition, 1997.

[28] B. D. Cullity and C. D. Graham, Introduction to Magnetic Materials, John Wiley \& Sons, 2009.

[29] G. Herzer, "Grain size dependence of coercivity and permeability in nanocrystalline ferromagnets," IEEE Transactions on Magnetics, vol. 26, no. 5, pp. 1397-1402, 1990.

[30] G. Herzer, "Nanocrystalline soft magnetic alloys," in Handbook of Magnetic Materials, vol. 10, North Holland, Amsterdam, The Netherlands, 1997.

[31] G. C. Papaefthymiou, "Nanoparticle magnetism," Nano Today, vol. 4, no. 5, pp. 438-447, 2009. 

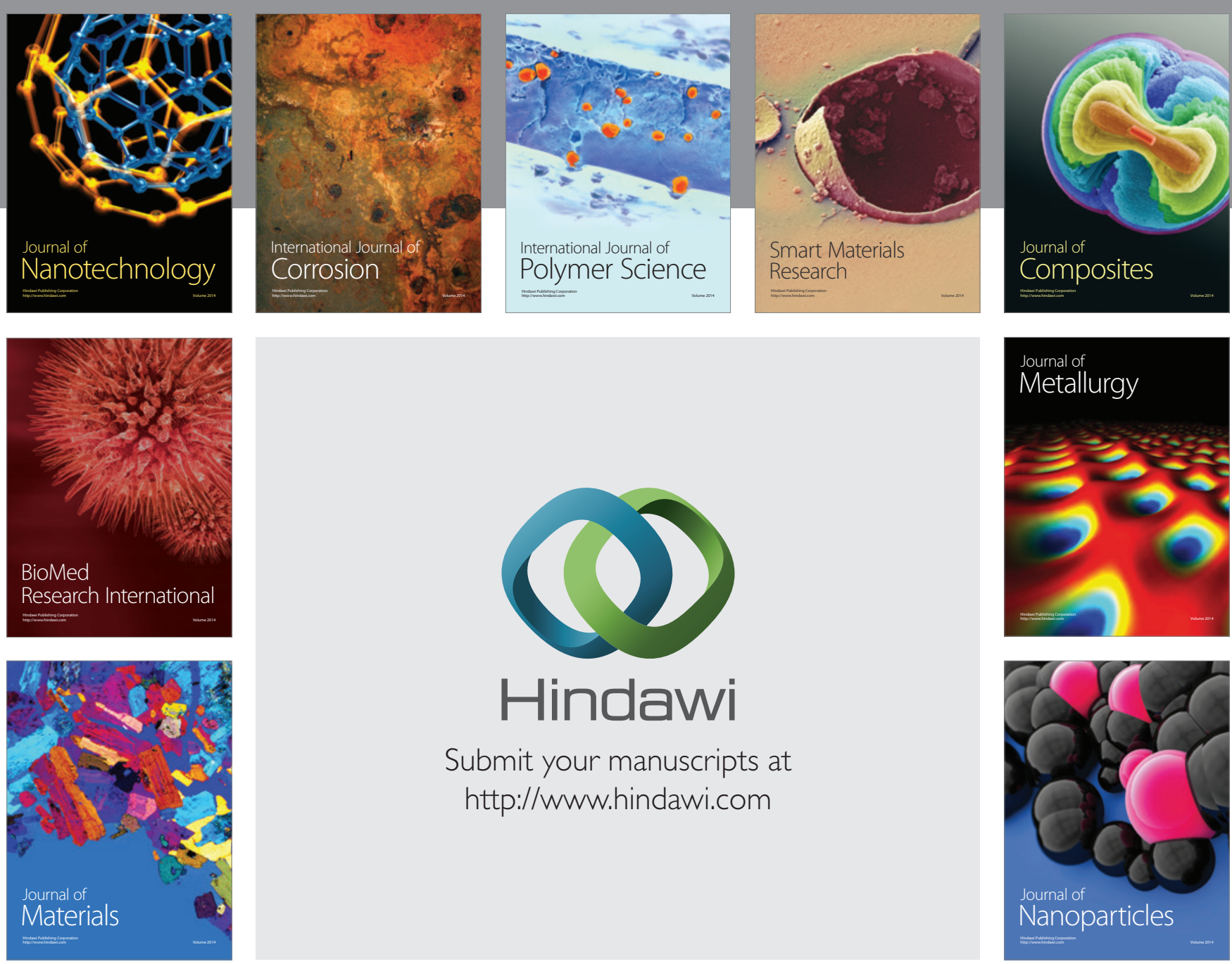

Submit your manuscripts at http://www.hindawi.com
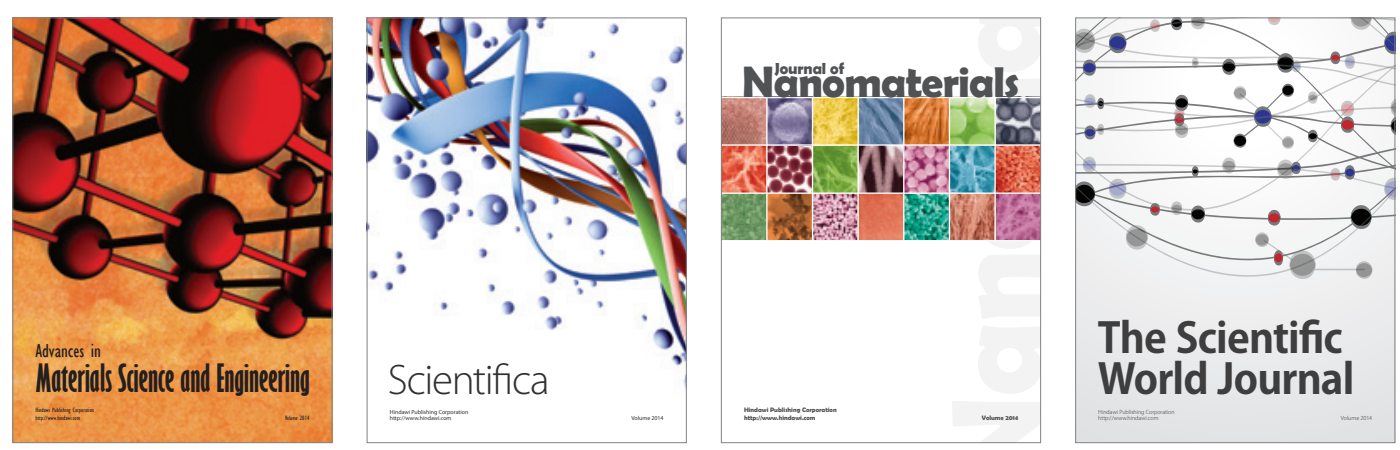

\section{The Scientific World Journal}
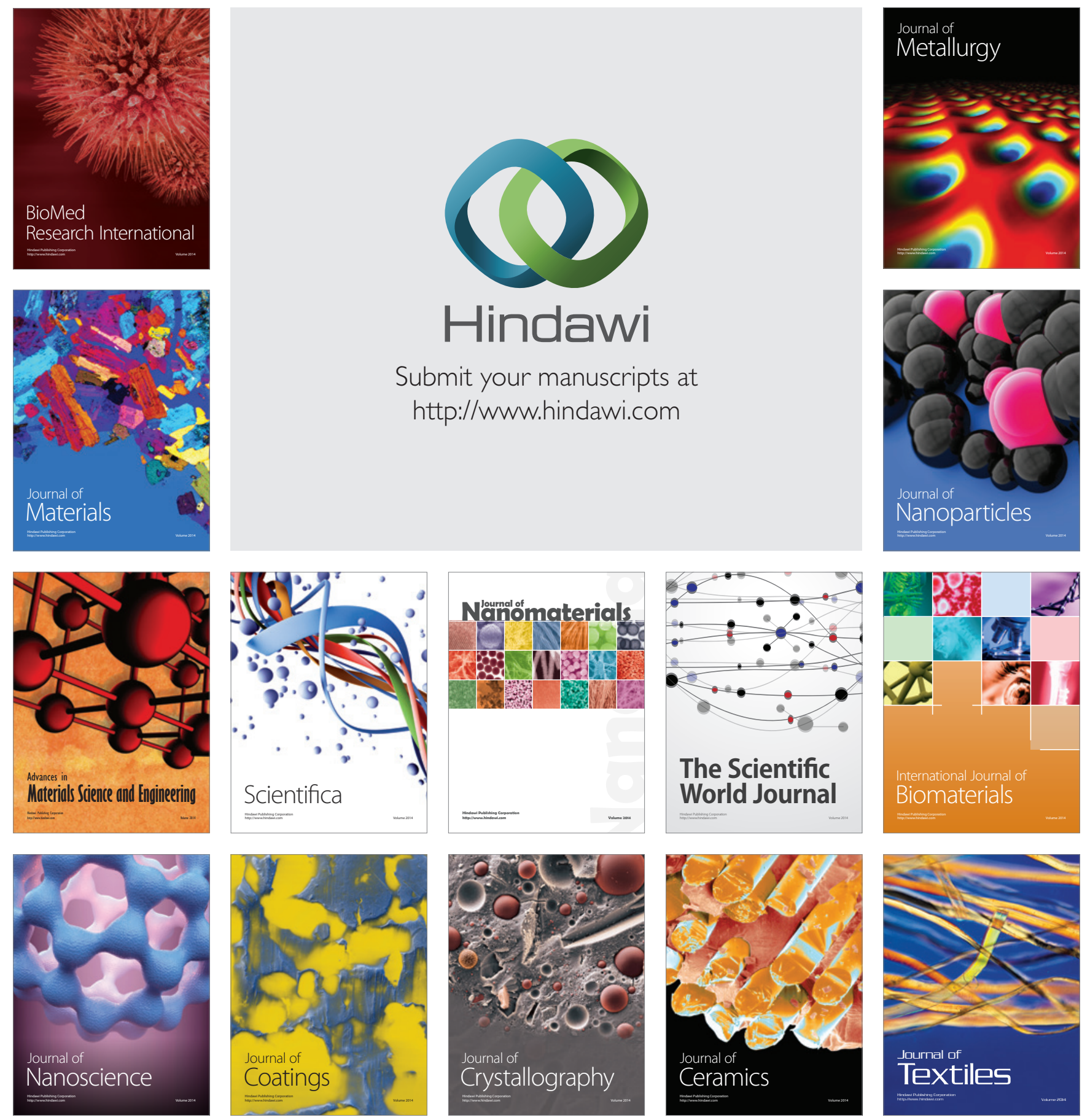